\title{
Experimental Direct Torque Control Induction Motor Drive with Modified Flux Estimation and Speed control Algorithm.
}

\author{
Bhoopendra singh ${ }^{1}$, Shailendra Jain ${ }^{2}$, Sanjeet Dwivedi ${ }^{3}$ \\ ${ }^{I}\left(R G T U\right.$, Bhopal), ${ }^{2}$ (MANIT Bhopal), ${ }^{3}$ (Danfoss Power Electronics, Denmark)
}

\begin{abstract}
An enhancement in dynamic performance of a traditional direct torque control (DTC) drive can be achieved by a robust speed control algorithm while the steady state performance depends upon an efficient flux estimation algorithm. In this paper a conventional PI controller in the speed control loop is replaced by a sliding mode speed controller and a modified low pass filter based digital integration algorithm with tunable cut off frequency is proposed for flux estimation. The proposed study is investigated through simulation and experimentally validated on a test drive.
\end{abstract}

Keywords - Direct torque control, Induction motor, modified low pass filter, sliding mode control

\section{INTRODUCTION}

In a direct torque control induction motor drive, the basic concept is to control both stator flux and electromagnetic torque of the machine simultaneously by the application of one of the six active full voltage vectors and two zero voltage vectors generated by an inverter. The stator flux and torque track their reference values within the limits of two hysteresis bands with two hysteresis comparators and a heuristic switching table to obtain quick dynamic response [1]-[3].

The steady state as well as the dynamic performance of the drive is closely related to the efficient implementation of flux and speed control algorithm. There are few well-known methods to estimate the stator flux. Most of them are voltage model based [3], where the flux and torque are estimated by sensing stator voltage and current. The methods based on voltage models are most preferable for sensor less drives since these methods are less sensitive to the parameter variations and does not require motor speed or rotor position signals. However, the estimation of stator voltage when the machine is operating at low speed introduces error in flux estimation which also affects the estimation of torque and speed in case of sensor less drive [4]-[10].

In a conventional DTC drive the basic voltage model based flux estimation is carried out by integrating the back emf of the machine. A pure integrator has the following limitations.

1. Any transduction error in measured stator current due to offset introduces DC component and hence results in integrator saturation.

2. Integration error due to incorrect initial values.

A commonly employed solution is to replace a pure integrator with a low pass filter [11] [12], however it is achieved at the expense of deteriorated low speed operation of the drive, when the operating frequency of the drive is lower than the cut off frequency of the low pass filter.

Flux estimation based on the current model is most suitable for low speed operation [13], however it is a parameter dependent method, which require rotor speed or position. Thus parameter independent operation, which makes a DTC drive more robust and reliable compared to a FOC drive, gets affected when current model based flux estimation is implemented .

In this paper a low pass filter based digital integration algorithm with tunable cutoff frequency is implemented for flux estimation and a sliding mode speed control algorithm is proposed to improve the dynamic response of the drive [14]. Thus the aim of this paper is to enhance the steady state as well as the dynamic performance of the drive while maintaining the simplicity of control algorithm. The proposed control strategy is illustrated by simulation and validated through experimental results.

\section{DTC OPERATION}

According to the DTC principle, an independent control of torque and flux can be achieved by the application of appropriate voltage vectors in such a way that the error between the estimated torque and flux with their respective reference values remains within the limits of hysteresis comparators. The desired voltage vectors to compensate the errors are selected based on the output of the torque and flux hysteresis comparator as well as the locus of stator flux vector.

From the basic equation governing induction motor operation stator flux $\lambda_{s}$ is given by

$$
\lambda_{s}=\int\left(V_{s}-R_{s} I_{s}\right) d t
$$

Neglecting the drop in stator resistance,

$$
\Delta \lambda_{s}=\overline{V_{s}} \Delta t
$$

Where $\Delta t$ is the time interval of application of the applied voltage vector. Electromagnetic torque in an Induction motor is given by (1)

$T_{e}=P \frac{L_{m}}{\sigma L_{s} L_{r}}\left|\lambda_{s}\right|\left|\lambda_{r}\right| \sin (\delta)$

Where

$\sigma=1-\frac{L_{m}^{2}}{L_{s} L_{r}}$ 
It can be concluded from (1) that an increment in torque can be achieved by increasing the angle between stator and rotor flux vector. Splitting the vector $\Delta \lambda_{s}$ into horizontal and orthogonal components it can be concluded that orthogonal component of $\Delta \lambda_{s}$ is responsible for torque control and the horizontal component controls the flux as shown in Fig. 1.

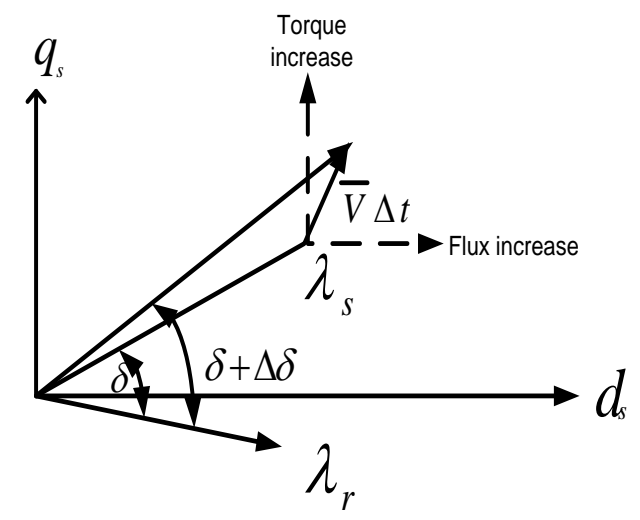

Fig. 1 Flux and torque control by the applied voltage vector in a DTC drive.

\section{III .FLUX ESTIMATION}

A well-known solution to the dc-offset and initial value problem with a pure integrator is to replace it with a low pass filter (LPF) with an appropriate cut off frequency. The mathematical expression of the low pass filter with a cut off frequency of $\omega_{c}$ can be given by (2) - (5)

$$
\begin{aligned}
& \lambda_{s \alpha}=\frac{1}{s+\omega_{c}}\left(E_{s \alpha}\right) \\
& \lambda_{s \beta}=\frac{1}{s+\omega_{c}}\left(E_{s \beta}\right)
\end{aligned}
$$

Which can be expressed in discrete form as
The value of the cutoff frequency $\omega_{c}$ has to be judicially chosen, because a cutoff frequency higher than operating frequency of the drive leads to flux distortion at low speeds. A possible solution to this problem is a modified LPF based flux estimator with cutoff frequency proportional to the synchronous frequency, as shown in Fig.2(a) .The relation between the cutoff frequency and synchronous frequency $\omega_{e}$ can be given by a simple relation $\omega_{c}=k \omega_{e}$.The typical range of $k$ lies between 0.1 and 0.5 and the synchronous frequency can be given by (6).

$$
\omega_{e}=\frac{E_{s \beta} \lambda_{s \alpha}-E_{s \alpha} \lambda_{s \beta}}{\left|\lambda_{s}\right|^{2}}
$$

\section{IV.SPEED CONTROL}

A sliding mode (SM) speed controller is proposed for obtaining a robust dynamic performance of the DTC drive. The schematic diagram of the speed controller is given in Fig.2 (b).The equations for modeling the SM speed controller are given by equations (7) - (9).

The rotor speed error can be given as

$X_{1}=N_{r}^{*}(k)-N_{r}(k)$

Where $N_{r}^{*}(k)$ is the reference speed at $\mathrm{k}^{\text {th }}$ sampling instant and $N_{r}(k)$ is the actual rotor speed. The rate of change of speed error in discrete form is given by (6)

$$
X_{2}=\frac{X_{1}(k)-X_{1}(k-1)}{\Delta t}
$$

$$
\begin{aligned}
& \lambda_{s \alpha}(k)=\frac{1}{1+\Delta t_{s} \omega_{c}}\left(\Delta t_{s} E_{s \alpha}(\mathrm{k})+\lambda_{s \alpha}(\mathrm{k}-1)\right) \\
& \lambda_{s \beta}(k)=\frac{1}{1+\Delta t_{s} \omega_{c}}\left(\Delta t_{s} E_{s \beta}(\mathrm{k})+\lambda_{s \beta}(\mathrm{k}-1)\right)
\end{aligned}
$$

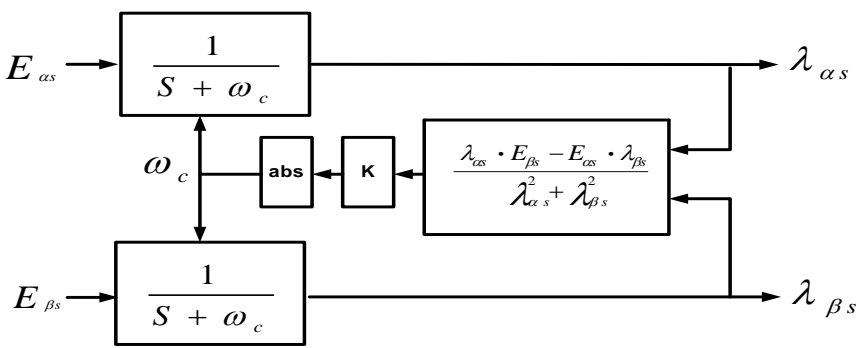

(a)

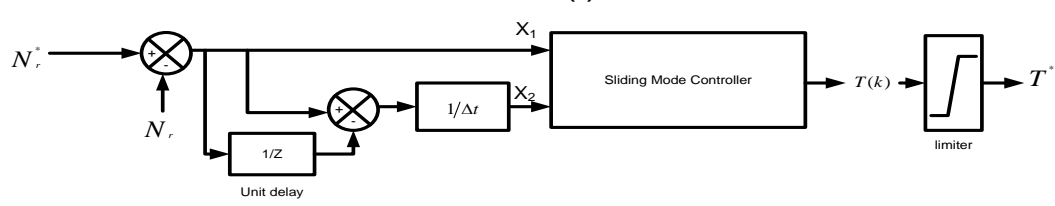

(b)

Fig. 2 (a) Flux estimation by modified low pass filter (b) sliding mode speed controller 
The output of the sliding mode controller is given as

$$
T(k)=C_{3} X_{1}(k) Y_{1}(k)+C_{4} X_{2}(k) Y_{2}(k)
$$

Reference torque command $\mathrm{T}^{*}(\mathrm{k})$ is obtained after limiting the output of the sliding mode controller. In the eqn. (9), $C_{3}$ and $\mathrm{C}_{4}$ are gains of sliding mode controller and $\mathrm{Y}_{1}(\mathrm{k})$ and $\mathrm{Y}_{2}(\mathrm{k})$ can be given as:

$$
\begin{aligned}
& Y_{1}(k)=+1 \text { if } Z_{1}(k) \geq 0 \\
& Y_{1}(k)=-1 \text { if } Z X 1(k)<0
\end{aligned}
$$

And, $\mathrm{Y}_{2}(\mathrm{k})=+1$ if $\mathrm{ZX} 2(\mathrm{k}) \geq 0$

$$
\mathrm{Y}_{2}(\mathrm{k})=-1 \text { if } \mathrm{ZX} 2(\mathrm{k})<0
$$

$\mathrm{Z}$ is switching line on which the sliding mode action occurs and is given by (10)

$$
\mathrm{Z}=\mathrm{C}_{1} \mathrm{X}_{1}(\mathrm{k})+\mathrm{C}_{2} \mathrm{X}_{2}(\mathrm{k})
$$

Where $\mathrm{C}_{1}$ and $\mathrm{C}_{2}$ are adjustable parameters .

\section{RESULTS AND DISCUSSION}

The steady state as well as dynamic performance of the proposed drive are investigated through simulations using Matlab/Simulink and are further validated experimentally.

A test drive set up developed in the laboratory is shown in Fig.3.The experimental test drive setup consists of the following elements:

1) Machine unit; a $0.75 \mathrm{~kW}, 410 \mathrm{~V}, 50-\mathrm{Hz}$ squirrel-cage induction motor with a shaft mounted tachogenerator for speed sensing coupled with dc generator for loading.
2) A power module with MOSFET based voltage source inverter with Hall Effect sensors and gate drive circuitry.

3) dSpace DS1104 control board.

The parameters of the motor for experimentation are as follows. $\mathrm{R}_{\mathrm{s}}=10.75 \Omega, \mathrm{R}_{\mathrm{r}}=9.28 \Omega \quad, \mathrm{L}_{\mathrm{s}}=\mathrm{L}_{\mathrm{r}}=51.9 \mathrm{mH}$, $\mathrm{P}=4$ and $\mathrm{L}_{\mathrm{m}}=479.9 \mathrm{mH}$. The sampling time of the DTC experiments is taken as $100 \mu \mathrm{s}$ while the dead time for the switches is $10 \mu \mathrm{s}$. The value of torque and flux hysteresis comparator bandwidth is takes as $0.5 \mathrm{Nm}$ and $0.005 \mathrm{wb}$. All experimental results are recorded using the Control Desk platform of dSpace DS1104 by saving the target variable as mat files.

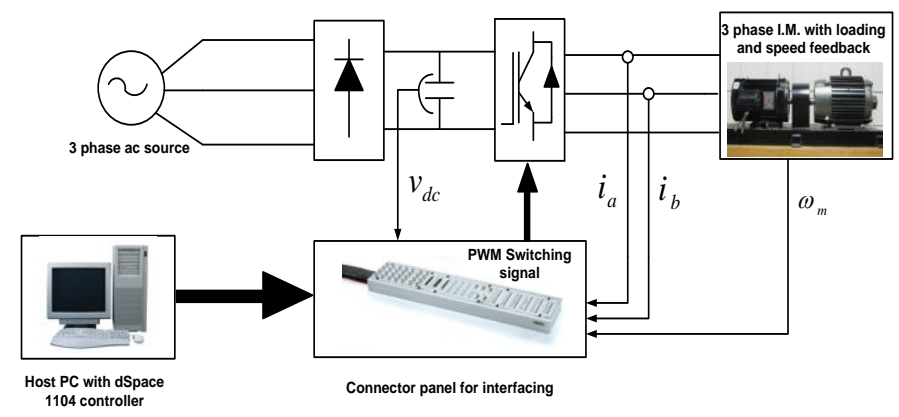

Fig.3 Experimental test drive set up.

The dynamic response of the drive was investigated for speed reversal and step increment in operating speed at full load .Fig. 4 shows the experimental and simulated results for a speed reversal at rated speed $(-1490 \mathrm{rpm}$ to $+1490 \mathrm{rpm})$. It can be verified from the experimental results that the time
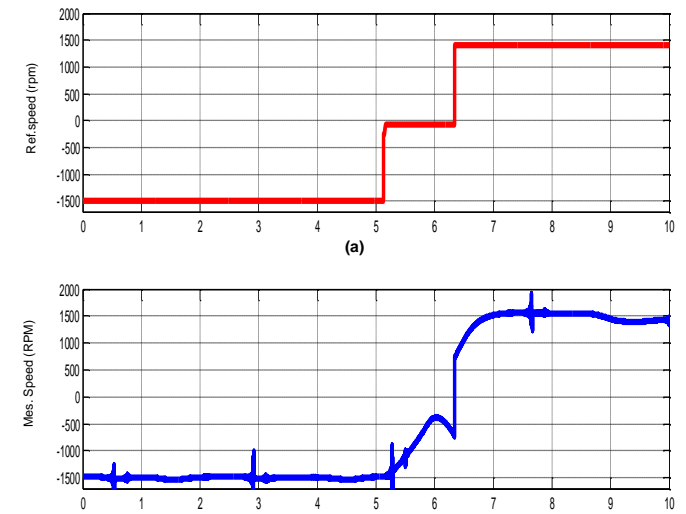

(b)

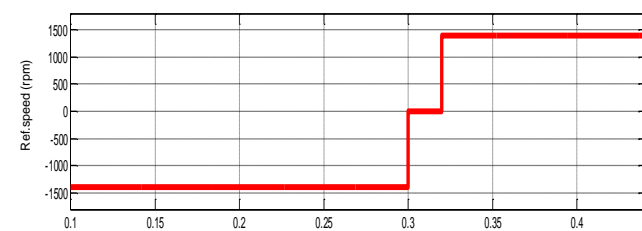

(c)

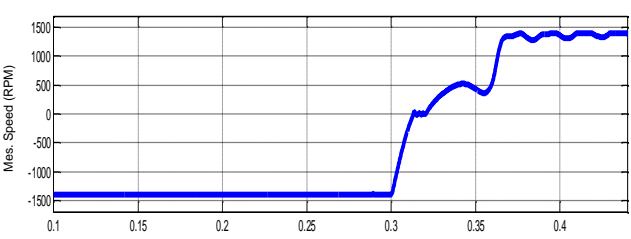

(d)

Fig.4 Experimental and simulated speed reversal dynamics (a) ref. speed (experimental)

(b) measured rotor speed (experimental) (c) ref. speed (simulation result) (d) rotor speed (simulated) 


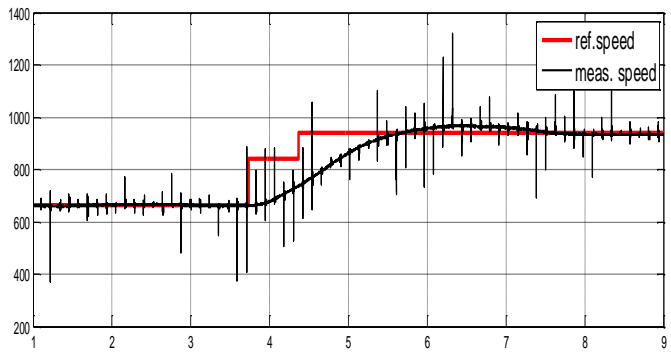

(a)

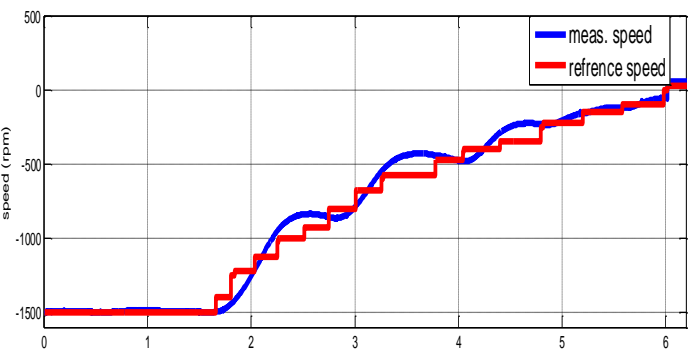

(b)

Fig.5 Experimental dynamic response for a step change in speed command input. (a) dynamic response for a two-step reference speed input in forward direction (b) dynamic response for a continuous variation in reference speed in reverse direction.
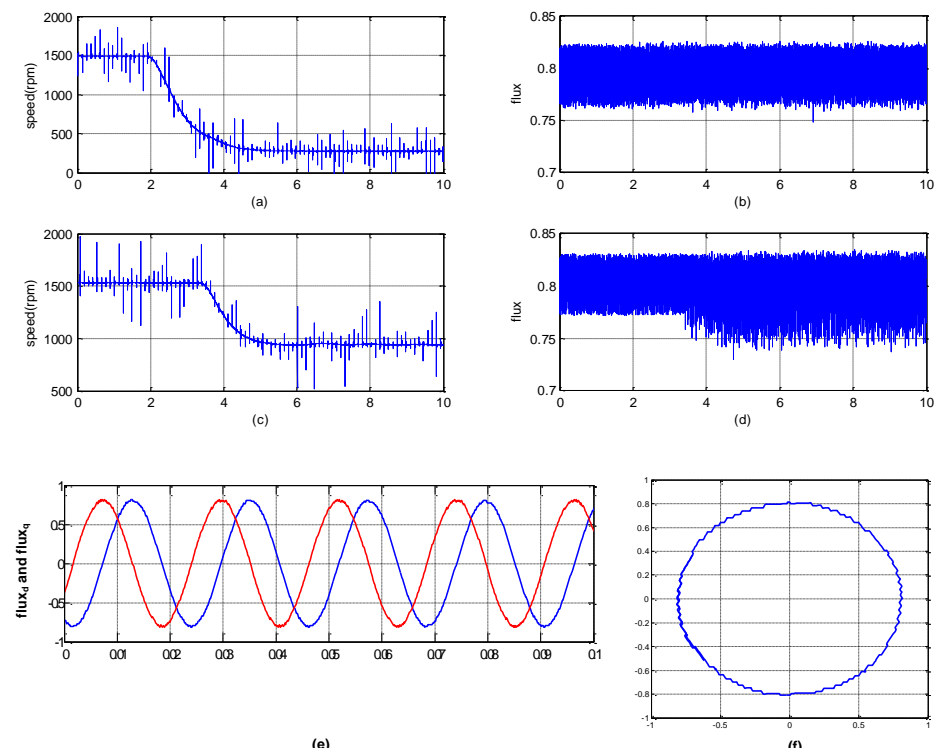

Fig.6 Experimental results to validate the effectiveness of the flux estimation algorithm (a) speed in rpm (b) flux response for step reduction in operating speed for modefied LPF method (c) speed in rpm (d) flux response of conventional LPF method (e) steady state Stator flux components $\left(\lambda_{\mathrm{s} \alpha}, \lambda_{\mathrm{s} \beta}\right)$ (f) flux trajectory.

taken by the drive to attain steady state speed after reversal is approximately 2 secs. Similar performance is also verified from the simulation results shown in Fig.4(c) and 4(d). The experimental drive response for a step input speed command is shown in Fig .5(a) and it can be verified from the experimental results that the actual speed reaches the reference speed with minimum overshoot and steady state error. To further study the speed tracking performance of the speed controller, the drive is subjected to a continuous change in reference speed shown in Fig.5 (b), which is achieved by the control desk platform of dspace having the feature of online change in an input parameter. From Fig.5(b) it can be seen that the actual rotor speed tracks the reference speed from $-1500 \mathrm{rpm}$ zero rpm .Thus a fast dynamic response validates the superiority of the speed control algorithm. The investigations on the proposed DTC drive are summarized in Table 1 .
Table.1 summary of the proposed investigation

\begin{tabular}{|c|c|}
\hline $\begin{array}{l}\text { Performance } \\
\text { parameters }\end{array}$ & Remarks \\
\hline $\begin{array}{l}\text { Flux } \\
\text { Response }\end{array}$ & $\begin{array}{l}\text { 1. Improved flux response due to the } \\
\text { modified flux estimation method having } \\
\text { tunable cutoff frequency during sudden } \\
\text { variation in operating speed } \\
\text { 2.Circular stator flux trajectory }\end{array}$ \\
\hline Speed control & $\begin{array}{l}\text { A fast dynamic response with sliding } \\
\text { mode speed controller. }\end{array}$ \\
\hline
\end{tabular}




\section{CONCLUSION}

An enhancement in steady state and dynamic performance of a DTC drive is achieved by implementing a modified integration algorithm based on a low pass filter with tunable cutoff frequency. An improved flux response during low speed operation with a circular flux trajectory has also been achieved by the proposed technique. Implementation of sliding mode algorithm in the speed control loop has resulted into a fast dynamic response of the drive.

\section{ACKNOWLEDGEMENTS}

This work was funded and supported by the All India Council of Technical Education, research promotion scheme (AICTE-RPS).

\section{REFERENCES}

[1] I.Takahashi and T.Noguchi, "A new quick-response and high efficiency control strategy of Induction Motor", IEEE Transactions on Industrial application, vol. 22, no 5, pp. 820-827,1986.

[2] M. Depenbrok, "Direct self-control (DSC) of inverterfed induction machine," IEEE Trans. Power Electron. vol. 3, no. 4, pp. 420-429, Oct. 1988.

[3] G. S. Buja and M. P. Kazmierkowski, "Direct Torque control of a PWM inverter-fed AC motors-A Survey," IEEE Trans. Ind. Electron., vol. IE-51, no. 4, pp. 744757, Aug. 2004.

[4] M. Shin, D.S. Hyun, S.B. Cho, and S.Y. Choe,"An improved stator Flux estimation for speed Sensorless stator Flux orientation control of induction motors", IEEE Trans. Power Electron.,vol. 15, pp.312 -318, 2000

[5] E. D. Mitronikas, A. N. Safacas, "An Improved Sensorless Vector-Control Method for an Induction Motor," IEEE Trans. Ind. Electron., Vol. 52, No. 6, Dec. 2005.

[6] J. Holtz, "Sensor less position control of induction motors-An emerging technology," IEEE Trans. Ind. Electron., vol. 45, pp.840-852, Dec. 1998.

[7] J. Holtz, "Drift and Parameter Compensated Flux Estimator for Persistent Zero-Stator-Frequency Operation of Sensorless-Controlled Induction Motors," IEEE Trans. Ind. Electron., vol. 39, no. 4, pp. 1052 1060, Aug. 2003.
[8] K. D. Hurst, T. G. Habetler, G. Griva, and F. Profumo, "Zero-speed tacholess IM Torque control: Simply a matter of stator voltage integration", IEEE Trans. Ind. Application, vol. 34, pp.790 -795,1998.

[9] B. K. Bose and N. R. Patel, "A programmable cascaded low-pass filter-based Flux synthesis for a stator Flux-oriented vector-controlled induction motor drive", IEEE Trans. Ind. Electron., vol. 44,pp.140$143,1997$.

[10] J. Holtz and J. Quan, "Sensorless vector control of induction motors at very low speed using a Nonlinear inverter model and parameter identification", Conf. Rec. IEEE-IAS Annu. Meeting, vol. 4, pp.26142621,2001.

[11] J. $\mathrm{Hu}$ and $\mathrm{B} . \mathrm{Wu}$, "New integration algorithms for estimating motor Flux over a wide speed range," IEEE Trans. Power Electron., vol. 13, pp.969-977, Sept. 1998.

[12] M. Hinkkanen, J Luomi," Modified integrator for voltage model Flux estimation of induction motors," IEEE Trans. Ind. Electronics, Vol. 50, No. 4,Aug. 2003.

[13] Bertoluzzo, M.; Buja, G.; Menis, R, “A Direct Torque Control Scheme for Induction Motor Drives using the Current Model Flux Estimation," Conf. Rec. IEEE Int. symposium, pp. 185 - 190, Nov. 2006.

[14] Singh.B, Singh.B.P. and Dwivedi.S, "DSP based implementation of Sliding Mode Speed Controller for Vector Controlled Permanent Magnet Synchronous Motor drive," in Proc. IICPE-2006, 2006, pp 22-27. 